\title{
Polytetrahydrofuran/Clay Nanocomposites by In Situ Polymerization and "Click" Chemistry Processes
}

\author{
Mehmet Atilla Tasdelen, ${ }^{\dagger, \ddagger}$ Wim Van Camp, ${ }^{\ddagger}$ Eric Goethals, ${ }^{\ddagger}$ Philippe Dubois, ${ }^{\S}$ \\ Filip Du Prez, ${ }^{*, \ddagger}$ and Yusuf Yagci ${ }^{*, \dagger}$
}

\begin{abstract}
Department of Chemistry, Istanbul Technical University, Maslak, TR-34469, Istanbul, Turkey, Department of Organic Chemistry, Polymer Chemistry Research Group, Ghent University, Krijgslaan 281 S-4, B-9000 Ghent, Belgium, and Center of Innovation and Research in Materials and Polymers (CIRMAP), Laboratory of Polymeric and Composite Materials (LPCM), University of Mons-Hainaut, Place du Parc 20, B-7000 Mons, Belgium
\end{abstract}

Received May 23, 2008; Revised Manuscript Received July 1, 2008

\begin{abstract}
Polytetrahydrofuran (PTHF)/clay nanocomposites were prepared by two routes: in situ cationic ring opening polymerization (CROP) and a method involving "click" chemistry. In the first method, PTHF chains were grown from the surface of the organo-modified montmorillonite clay by CROP of tetrahydrofuran (THF) through the hydroxyl functions of the clay by using trifluoromethanesulfonic anhydride, in the presence of 2,6di-tert-butylpyridine as proton trap and dichloromethane as solvent. The polymerizations were affected by the clay content ratios. The living characteristics of the polymerization were demonstrated by the semilogarithmic first order kinetic plot. In the second method, CROP of THF has been performed independently to produce alkynefunctionalized PTHF and the obtained polymers were subsequently anchored to azide-modified clay layers by a "click" reaction. The exfoliated polymer/clay nanocomposites obtained by both methods were characterized and compared by X-ray diffraction spectroscopy, thermogravimetric analysis, and transmission electron microscopy. Compared to the virgin polymer, the nanocomposites exhibited improved thermal stabilities regardless of the preparation method. However, the nanocomposites prepared by the "click" chemistry approach appeared to be thermally more stable than those prepared by in situ polymerization. Moreover, the "click" chemistry method also provided better exfoliation.
\end{abstract}

\section{Introduction}

Polymer/clay nanocomposites represent a new class of materials, which have attracted much attention because of their excellent physical properties such as high dimensional stability, gas barrier performance, flame retardancy, and mechanical strength when compared to the pure polymer or conventional composites (micro- and macro composites). ${ }^{1-3}$ Three methods have been developed over time for the synthesis of polymer/ clay nanocomposites: solution exfoliation, melt intercalation, and in situ intercalative polymerization. ${ }^{4}$ Solution exfoliation has been used with water-soluble polymers to produce mostly intercalated nanocomposites because of the need for large amounts of the solvent to ensure a good clay dispersion. ${ }^{5}$ Melt intercalation is a method to enable mixing of the layered silicate with the polymer matrix in the molten state. This solvent-free method requires the polymer to be compatible with the clay layer surfaces. In the intercalative polymerization technique, the monomer, together with the initiator and catalyst, is intercalated within the silicate layers and the polymerization is initiated either thermally or chemically in situ. The chain growth in the clay galleries triggers the clay exfoliation and, hence, the nanocomposite formation. In recent years, polymer/clay nanocomposites have been prepared by various in situ polymerization methods such as ring-opening polymerization, ${ }^{6-9}$ controlled radical polymerization, ${ }^{9-20}$ conventional free radical polymerization, ${ }^{21-26}$ cationic polymerization, ${ }^{26,27}$ and living anionic polymerization. $^{28}$

* To whom correspondence should be addressed. Tel.: +90-2122853241(Y.Y.); +32-9-2644503(F.D.P.). Fax: +90-212-2856386 (Y.Y.); +32-9-2644972 (F.D.P.). E-mail: yusuf@itu.edu.tr (Y.Y.); filip.duprez@ ugent.be (F.D.P.).

Istanbul Technical University.

Ghent University.

${ }^{\S}$ University of Mons-Hainaut.
Polytetrahydrofuran (PTHF) is an important soft segment for producing thermoplastic elastomers such as polyester and polyurethane materials. ${ }^{29}$ In these applications, PTHF is valued as a precursor leading to products with outstanding hydrolytic stability at elevated temperatures, high fungal resistance, superior abrasion resistance, excellent resiliency, and attractive dynamic properties. PTHF is obtained by cationic ring opening polymerization (CROP) of tetrahydrofuran (THF) by using a wide range of conventional and photo initiators. The living character of the polymerization makes it possible to prepare polymers with well-defined end group functional and a narrow molecular weight distribution by using a functional initiator or termination agent. To the best of our knowledge, no examples of the synthesis of PTHF/clay nanocomposites have been reported so far.

The Huisgen 1,3-dipolar cycloaddition reaction of azides and terminal alkynes, catalyzed by copper(I) complexes is known as one of most efficient "click" reactions because of its high yield, short reaction time, mild reaction conditions, and a high tolerance toward other functional groups. 30,31 This "click" reaction has been applied to macromolecular engineering, ${ }^{32-37}$ surface modification $^{38}$ of both nanoparticles ${ }^{39,40}$ and silica, ${ }^{41}$ functionalization of carbon nanotubes, ${ }^{42}$ generation of nanostructured semiconductors, ${ }^{43}$ construction of degradable networks, ${ }^{44}$ and so on. However, "click" chemistry has never been applied for the synthesis of polymer/clay nanocomposites.

In this work, we report two effective routes for the synthesis of PTHF/clay nanocomposites, namely, (1) in situ CROP and (2) a method involving "click" chemistry. In the first approach, the nanocomposites have been prepared by the CROP of THF that is initiated in the intercalated layers of the clay. In the second approach, CROP of THF has been performed to produce alkyne-functionalized PTHF and the obtained polymers were subsequently anchored to azide-modified clay layers by a "click" reaction. In principle, this approach can be extended to the 
Table 1. Polymerization of Tetrahydrofuran in the Presence of $\mathbf{1}$, 3 , and $5 \%$ of Clay (MMT- $\left.\left(\mathrm{CH}_{2} \mathrm{CH}_{2} \mathrm{OH}\right)_{2}\right)$ and $\mathrm{TfO}_{2}$ at $20{ }^{\circ} \mathrm{C}$

\begin{tabular}{lcccccc}
\hline samples & $\begin{array}{c}\text { clay content } \\
(\text { wt } \%)\end{array}$ & $\begin{array}{c}\text { time } \\
(\mathrm{min})\end{array}$ & $\begin{array}{c}\text { conv. } \\
(\%)\end{array}$ & $\begin{array}{c}M_{\mathrm{n}, \mathrm{th}}{ }^{b} \\
\left(\mathrm{~g} \mathrm{~mol}^{-1}\right)\end{array}$ & $\begin{array}{c}M_{\mathrm{n}}{ }^{c} \\
\left(\mathrm{~g} \mathrm{~mol}^{-1}\right)\end{array}$ & $M_{\mathrm{w}} / M_{\mathrm{n}}$ \\
\hline NC-115 & 1 & 15 & 8 & 6700 & 6300 & 1.10 \\
NC-130 & 1 & 30 & 9 & 7500 & 6800 & 1.09 \\
NC-160 & 1 & 60 & 13 & 10800 & 7800 & 1.36 \\
NC-315 & 3 & 15 & 21 & 6000 & 5300 & 1.15 \\
NC-330 & 3 & 30 & 27 & 8200 & 8500 & 1.21 \\
NC-360 & 3 & 60 & 37 & 9900 & 8300 & 1.40 \\
NC-515 & 5 & 15 & 38 & 6400 & 5100 & 1.14 \\
NC-530 & 5 & 30 & 56 & 9200 & 8500 & 1.22 \\
NC-560 & 5 & 60 & 85 & 13800 & 14200 & 1.43
\end{tabular}

${ }^{a}$ Determined by gravimetric analysis. ${ }^{b} M_{\mathrm{n}, \mathrm{th}}=[M]_{0} /[I] \times M_{\mathrm{THF}} \times$ conversion $+\mathrm{T}-\left(\mathrm{CH}_{2} \mathrm{CH}_{2} \mathrm{OH}\right)_{2}$, assuming that all triflate groups of $\mathrm{Tf}_{2} \mathrm{O}$ and hydroxyl groups of MMT- $\left(\mathrm{CH}_{2} \mathrm{CH}_{2} \mathrm{OH}\right)_{2}$ are active. ${ }^{c}$ Polystyrene was used as a standard and a correction factor, measured for linear polytetrahydrofuran, of 0.44 was used.

combination of azide-modified clay with any other alkyne containing polymers.

The resulting exfoliated polymer/clay nanocomposites have been characterized by X-ray diffraction (XRD) spectroscopy, thermogravimetric analysis (TGA), and transmission electron microscopy (TEM).

\section{Experimental Section}

Materials. Organo-modified clay, Cloisite 30B (MMT$\left.\left(\mathrm{CH}_{2} \mathrm{CH}_{2} \mathrm{OH}\right)_{2}\right)$ was kindly supplied by Southern Clay Products (Gonzales, TX). The clay is a montmorillonite modified by methyl bis(2-hydroxyethyl) (tallow alkyl) ammonium ions. The organic content of the organo-modified montmorillonite, determined by TGA, was 21 wt $\%$. Before use, the clay was dried under vacuum at $110{ }^{\circ} \mathrm{C}$ for $1 \mathrm{~h}$. Tetrahydrofuran (THF; Aldrich HPLC grade) was dried on sodium wire under reflux in the presence of traces of benzophenone until a blue color persisted and was used directly after distillation. Dichloromethane (Acros, HPLC grade) was stored on calcium hydride and used after distillation. Trifluoromethanesulfonic anhydride $\left(\mathrm{Tf}_{2} \mathrm{O}\right.$; Acros $\left.98 \%\right)$, methyl trifluoromethanesulfonate (MeOTf; Acros 98\%), and triethylamine (Aldrich, HPLC grade) were purified by distillation just before use. Sodium azide $\left(\mathrm{NaN}_{3}\right.$, Acros $\left.99 \%\right)$, copper(II) sulfate $\cdot 5 \mathrm{H}_{2} \mathrm{O}\left(\mathrm{CuSO}_{4}\right.$, Acros $\left.99 \%\right)$, L-ascorbic acid sodium salt (NaAsc, Acros 99\%), 2,6-di-tertbutylpyridine (DTBP; Maybridge Chemicals >97\%), methanesulfonyl chloride (Acros 99.5\%), lithium bromide (LiBr, Fluka 98\%), propargyl alcohol (Aldrich, 99\%), propargyl methacrylate (Lancaster, 98\%), dimethyl sulfoxide (DMSO, Acros HPLC grade), methanol (Acros HPLC grade), ethanol (Acros 96\%), and pentane (technical) were used as received.

In Situ Polymerization of THF. A typical polymerization procedure is as follows (Table 1, entry 1). MMT- $\left(\mathrm{CH}_{2} \mathrm{CH}_{2} \mathrm{OH}\right)_{2}$ clay $(0.18 \mathrm{~g}, 1 \mathrm{wt} \%$ with respect to THF) was added in a twonecked $50 \mathrm{~mL}$ flask and dried under vacuum at $110{ }^{\circ} \mathrm{C}$ for $1 \mathrm{~h}$. Initiator $\mathrm{Tf}_{2} \mathrm{O}(0.50 \mathrm{~mL}, 2.97 \mathrm{mmol})$, DTBP $(1 \mathrm{~mL}, 4.46 \mathrm{mmol})$, and $\mathrm{CH}_{2} \mathrm{Cl}_{2}(7 \mathrm{~mL})$ were added to the flask under a nitrogen atmosphere. The mixture was stirred for $1 \mathrm{~h}$ at $0{ }^{\circ} \mathrm{C}$. The initiator solution was brought to $20^{\circ} \mathrm{C}$, after which a large amount of THF $(20 \mathrm{~mL}, 244 \mathrm{mmol})$ was introduced. After a polymerization time of, respectively, 15,30 , and $60 \mathrm{~min}$ at $20^{\circ} \mathrm{C}$, the polymerization was terminated by adding $1 \mathrm{~mL}$ of methanol. The polymer was then precipitated in cold pentane $\left(-20^{\circ} \mathrm{C}\right)$, filtered off on a cold glass filter, washed with cold pentane, and finally dried in vacuum.

Synthesis of Alkyne-Functionalized PTHF (PTHF-Alkyne). In a two-necked flask (flame-dried) fitted with a magnetic stirrer, an inlet for dry nitrogen, and a rubber septum, THF $(40.0 \mathrm{~mL}, 488$ $\mathrm{mmol})$ was introduced. The polymerization was initiated with methyl triflate $(0.11 \mathrm{~mL}, 0.97 \mathrm{mmol})$ at $20{ }^{\circ} \mathrm{C}$. After a polymerization time of, respectively, 15,30 , and $60 \mathrm{~min}$ at $20{ }^{\circ} \mathrm{C}$, with respect to PTHF samples 1, 2, and 3 in Table 2, propargyl alcohol $(1 \mathrm{~mL}, 17 \mathrm{mmol})$ was added as a terminating agent. The polymer was then precipitated in cold pentane $\left(-20^{\circ} \mathrm{C}\right)$, filtered off on a
Table 2. Cationic Ring Opening Polymerization of Tetrahydrofuran Initiated by Propargyl Alcohol in the Presence of MeOTf, at $20^{\circ} \mathrm{C}\left([M]_{0} /[\right.$ MeOTf $\left.]=500\right)$

\begin{tabular}{ccccccc}
\hline samples & $\begin{array}{c}\text { time } \\
(\mathrm{min})\end{array}$ & $\begin{array}{c}\text { conv }^{a}{ }^{a} \\
(\%)\end{array}$ & $\begin{array}{c}M_{\mathrm{n}, \mathrm{th}}{ }^{b} \\
\left(\mathrm{~g} \cdot \mathrm{mol}^{-1}\right)\end{array}$ & $\begin{array}{c}M_{\mathrm{n}, \mathrm{NMR}}{ }^{c} \\
\left(\mathrm{~g} \cdot \mathrm{mol}^{-1}\right)\end{array}$ & $\begin{array}{c}M_{\mathrm{n}}{ }^{d} \\
\left(\mathrm{~g} \cdot \mathrm{mol}^{-1}\right)\end{array}$ & $M_{\mathrm{w}} / M_{\mathrm{n}}$ \\
\hline PTHF-15 & 15 & 7 & 2600 & 3800 & 3200 & 1.26 \\
PTHF-30 & 30 & 11 & 4000 & 4300 & 4900 & 1.15 \\
PTHF-60 & 60 & 18 & 6500 & 11300 & 8500 & 1.11
\end{tabular}

${ }^{a}$ Determined by gravimetric analysis. ${ }^{b} M_{\mathrm{n}, \mathrm{th}}=[M]_{0} /[I] \times M_{\mathrm{THF}} \times$ conversion $+M_{\text {propargyl alcohol. }}{ }^{c}$ Calculated from ${ }^{1} \mathrm{H}$ NMR spectroscopy. ${ }^{d}$ Polystyrene was used as a standard and a correction factor, measured for linear polytetrahydrofuran, of 0.44 was used.

cold glass filter, washed with cold pentane, and finally dried in vacuum.

Synthesis of Azide-Functionalized Montmorillonite Clay (MMT-N $)_{3}$. Methyl bis(2-hydroxyethyl) (tallow alkyl) ammoniumorganomodified clay (MMT- $\left(\mathrm{CH}_{2} \mathrm{CH}_{2} \mathrm{OH}\right)_{2}, 4.50 \mathrm{~g}, 5.3 \mathrm{mmol}, \mathrm{OH}$ content) and triethylamine $(3.7 \mathrm{~mL}, 26.5 \mathrm{mmol})$ were added in THF $(200 \mathrm{~mL})$ and cooled to $0{ }^{\circ} \mathrm{C}$. Methanesulfonyl chloride $(2.1 \mathrm{~mL}$, $26.5 \mathrm{mmol}$ ) was added dropwise while stirring. The reaction mixture was allowed to heat up to room temperature and stirred overnight. Solvent was removed by rotary evaporation, and ethanol $(200 \mathrm{~mL})$ was added to the reaction mixture. Sodium azide $(1.72 \mathrm{~g}, 26.5$ mmol) was added, and the reaction mixture was refluxed overnight. After cooling to room temperature and removing the solvent by rotary evaporation, ether $(200 \mathrm{~mL})$ was added to the crude reaction mixture and washed three times with a saturated $\mathrm{NaCl}$ aqueous solution. The clay was then filtered off on a cold glass filter, washed with water, and finally dried in vacuum.

"Click" Coupling Reaction between Propargyl Methacrylate and Azide-Functionalized Montmorillonite Clay. Azidefunctionalized montmorillonite clay $(0.5 \mathrm{~g}, 6 \mathrm{mmol})$, propargyl methacrylate $(0.4 \mathrm{~mL}, 3 \mathrm{mmol})$, and DMSO $(20 \mathrm{~mL})$ were added in a round-bottomed flask and stirred. A solution of $\mathrm{CuSO}_{4}(0.02$ $\mathrm{g}, 0.12 \mathrm{mmol}$ ) in $1 \mathrm{~mL}$ of water was added to the mixture, followed by addition of a solution of sodium ascorbate $(0.09 \mathrm{~g}, 0.45 \mathrm{mmol})$ in $1 \mathrm{~mL}$ of water. The mixture was heated in an oil bath at $70{ }^{\circ} \mathrm{C}$ overnight. The particles were recovered by centrifugation at 3000 rpm for $30 \mathrm{~min}$. Then they are redispersed in water and the mixture was centrifuged; this cycle was repeated four times. Finally, the particles were placed in a Soxhlet extractor and extracted with THF for $18 \mathrm{~h}$ and dried in vacuum.

"Click" Coupling Reaction between Alkyne-Functionalized PTHF and azide-Functionalized Montmorillonite Clay. Azidemontmorillonite clay ( $0.25 \mathrm{~g}, 3 \mathrm{mmol})$, alkyne functionalized PTHF $(0.5 \mathrm{~g}, 1.5 \mathrm{mmol})$, and DMSO $(20 \mathrm{~mL})$ were added in a roundbottomed flask and stirred. A solution of $\mathrm{CuSO}_{4}(0.02 \mathrm{~g}, 0.12 \mathrm{mmol})$ in $1 \mathrm{~mL}$ of water was added to the mixture, followed by addition of a solution of sodium ascorbate $(0.09 \mathrm{~g}, 0.45 \mathrm{mmol})$ in $1 \mathrm{~mL}$ of water. The mixture was heated overnight in an oil bath at $70{ }^{\circ} \mathrm{C}$. The particles were recovered by the same procedure as described above.

Polymer Separation. Polymer bound on the clay was cleaved off by refluxing the polymer/clay nanocomposite with $\mathrm{LiBr}$ in tetrahydrofuran (THF) with overnight stirring. ${ }^{7}$ The cleaved polymers were separated from the solid clay nanoparticles by centrifugation. ${ }^{1} \mathrm{H}$ NMR, GPC, and TGA analyses were performed on the polymer clay nanocomposite and the detached polymer.

Techniques. ${ }^{1} \mathrm{H}$ NMR spectra were recorded in $\mathrm{CDCl}_{3}$ at room temperature with a Bruker AM500 spectrometer. GPC analysis was performed on a Waters instrument using a refractive index detector (2410 Waters) equipped with Waters Styragel $10^{3}-10^{4}-10^{5} \AA$ serial columns $(5 \mu \mathrm{m}$ particle size $)$ at $35^{\circ} \mathrm{C}$. PS standards were used for calibration and $\mathrm{CHCl}_{3}$ as eluent at a flow rate of $1.5 \mathrm{~mL} /$ min. Fourier transform attenuated total-reflectance infrared (FTATR-IR) spectra of the original and modified TM were recorded on a BIO-RAD FT-ATR-IR spectrometer 575C using 64 scans at a resolution of $4 \mathrm{~cm}^{-1}$. Thermogravimetric analysis (TGA) was performed with a Mettler Toledo TGA/SDTA851e instrument under air atmosphere at a heating rate of $20^{\circ} \mathrm{C} / \mathrm{min}$ between 25 and 800 
Scheme 1. Preparation of Polytetrahydrofuran/Montmorillonite Clay Nanocomposites by In Situ Cationic Ring Opening Polymerization

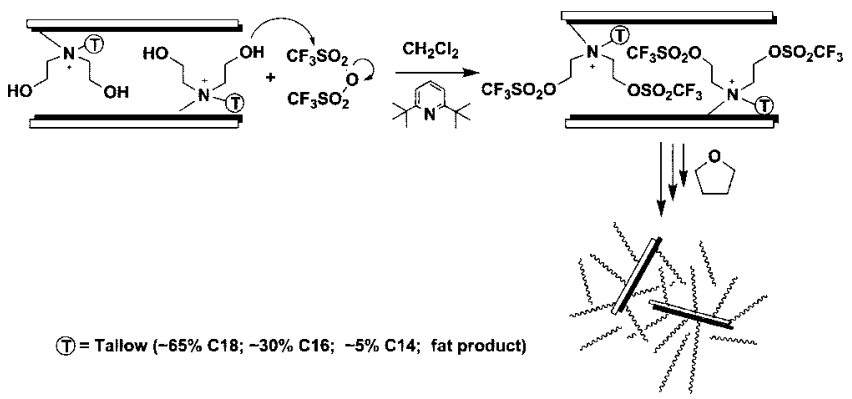

${ }^{\circ} \mathrm{C}$. The powder X-ray diffraction (XRD) measurements were performed on a Siemens D5000 X-ray diffractometer equipped with graphite-monochromatized $\mathrm{Cu} \mathrm{K} \alpha$ radiation $(\lambda=1.5405 \AA$ A). TEM micrographs were obtained with a Philips CM100 apparatus using an acceleration voltage of $100 \mathrm{kV}$. Ultrathin sections (ca. $80 \mathrm{~nm}$ thick) were cut at $-100{ }^{\circ} \mathrm{C}$ from $3 \mathrm{~mm}$ thick hot-pressed plates by using a Reichert-Jung Ultracut FC4E microtome equipped with a diamond knife. Because of the large difference in electron density between silicate and polymer matrix, no selective staining was required.

\section{Results and Discussion}

For the preparation of PTHF/clay nanocomposites by the in situ polymerization method, the hydroxyl functions of the modified intercalated montmorillonite clay (MMT- $\left(\mathrm{CH}_{2} \mathrm{CH}_{2-}\right.$ $\mathrm{OH})_{2}$ ) are reacted with trifluoromethanesulfonic anhydride $\left(\mathrm{TfO}_{2}\right)$, in the presence of DTBP as proton trap and dichloromethane as solvent, to produce the corresponding triflate ester that is known to be an initiator for the CROP of THF. Then, a large amount of THF monomer is added. ${ }^{45}$ After the prescribed reaction time, the process directly leads to the formation of the PTHF/clay nanocomposites (Scheme 1).

A series of polymerizations were conducted using different clay contents while reaction times were also varied to gain more insight in the CROP initiated on the clay surface. The results are shown in Table 1 and Figures 1 and 2. As can be seen from Table 1, the molecular weights of the polymers, which are obtained after cleaving them off from the clay by $\mathrm{LiBr}$, are higher than the expected molecular weight. A possible reason for this discrepancy may be ascribed to the complex nature of the intercalated initiating sites and to the fact that a fraction of the hydroxyl groups may not be activated by triflic anhydride. However, the polydispersity indices are quite low and remain below 1.4, even at high conversions. The corresponding semilogarithmic first order kinetic plot is depicted in Figure 1a. The linear relationship indicates that the living characteristics of CROP also apply to the present system. The polymerizations exhibit different rate constants, which show that the polymerization is affected by the clay content ratios. Furthermore, the molecular weights of the polymers $\left(M_{\mathrm{n}}\right)$ increase linearly with monomer conversion as expected for a living polymerization (see Figure 1b).

XRD analyses of the PTHF/clay nanocomposites that are obtained by using, respectively, 1, 3, and 5 wt \% of organomodified nanofiller, are consistent with an exfoliated structure. The $\mathrm{d}_{001}$ spacing for organo-modified MMT initially present at $1.86 \mathrm{~nm}$ completely disappears and the PTHF characteristic diffraction peaks emerge at 0.46 and $0.38 \mathrm{~nm}$ as illustrated by Figure 2 for the PTHF/clay nanocomposite samples.

The second approach that we investigated for the preparation of PTHF/clay nanocomposites involves "click" chemistry. In this case, alkyne-functionalized PTHF molecules were synthe-

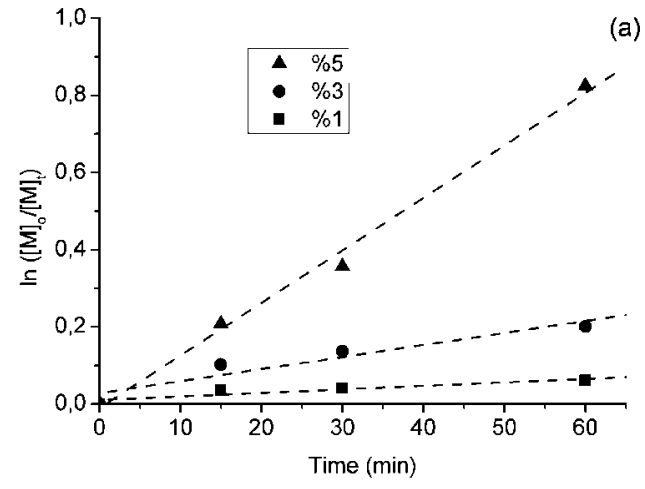

(a)

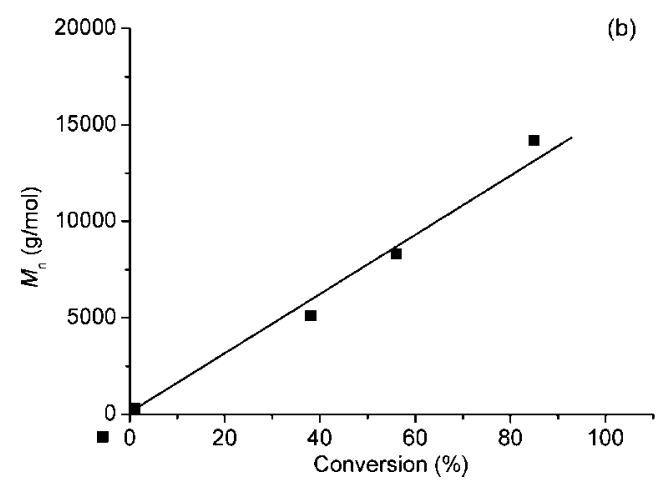

Figure 1. Plots of $\ln \left([M]_{0} /[M]_{\mathrm{t}}\right)$ vs time for the polymerization of tetrahydrofuran at $20{ }^{\circ} \mathrm{C}$ in the presence of 1,3 , and $5 \%$ of MMT$\left(\mathrm{CH}_{2} \mathrm{CH}_{2} \mathrm{OH}\right)_{2}$ (a) and evolution of $M_{\mathrm{n}}$ determined by GPC as a function of the monomer conversion for the polymerization of tetrahydrofuran at $20{ }^{\circ} \mathrm{C}$ in the presence of $5 \%$ of MMT- $\left(\mathrm{CH}_{2} \mathrm{CH}_{2} \mathrm{OH}\right)_{2}$ (b).

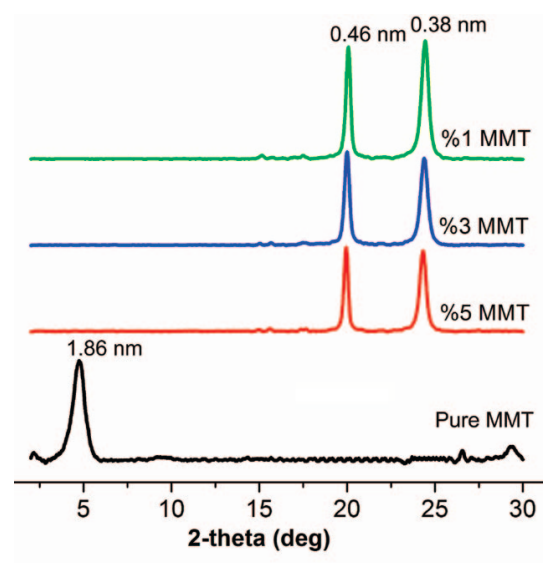

Figure 2. X-ray diffraction curves of pure MMT, PTHF-1\%MMT, PTHF-3\%MMT, and PTHF-5\% MMT nanocomposites.

sized by CROP using propargyl alcohol as the termination agent, while the silica layers of the clay were modified with an azide functionality according to the procedure reported for the conversion of hydroxyl groups into azides. ${ }^{46}$ Subsequently, the PTHF is attached onto the surface and into the interlayer of the silicate, using the copper catalyzed(I) Huisgen 1,3-dipolar cycloaddition reaction between azides and alkynes.

For the introduction of azide functionalities on the surface of the silica nanolayers, methanesulfonyl chloride was used to convert the hydroxyl groups into methanesulfonate groups, which were subsequently reacted with sodium azide to yield the desired clay "click" component (Scheme 2). The presence of the azide group was verified by FTIR absorption at 2050 $\mathrm{cm}^{-1}$ (Figure 3). However, the presence of a broadband at 3410 $\mathrm{cm}^{-1}$ indicates that a fraction of the hydroxyl groups on the 
Scheme 2. Azide-Functionalized Montmorillonite Clay and its "Click" Reactions with Propargyl Methacrylate (a) and Alkyne-Functionalized Polytetrahydrofuran (b)
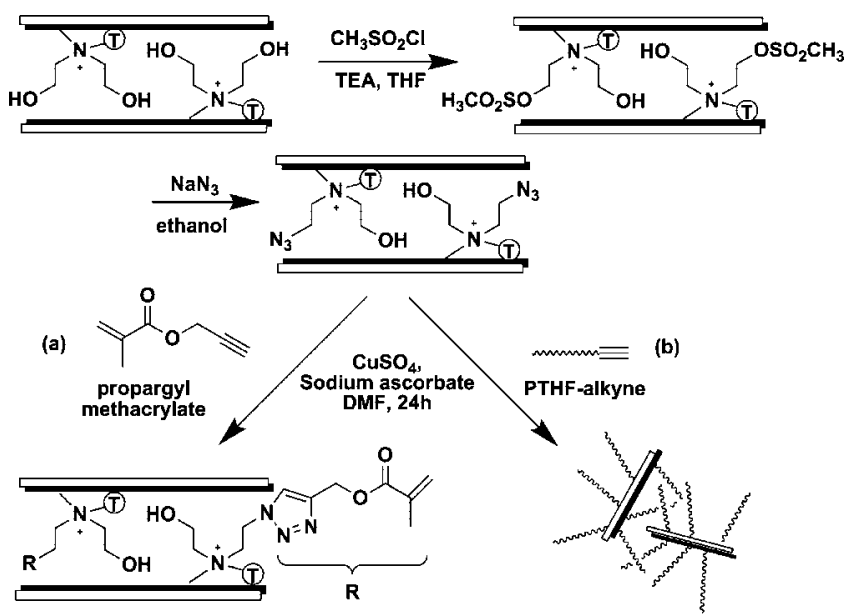

(T) = Tallow $(\sim 65 \% \mathrm{C} 18 ; \sim 30 \% \mathrm{C} 46 ; \sim 5 \% \mathrm{C} 14$; fat product $)$

surface of the layers has not been converted to azide functionalities.

Alkyne-functionalized PTHF, the other "click" component, was prepared by terminating living PTHF chains with propargyl alcohol (Scheme 2), based on earlier developed synthetic routes for other end-functionalized PTHF systems. ${ }^{47}$ As can be seen from Table 2, the molecular weights determined by GPC and ${ }^{1} \mathrm{H}$ NMR measurements were in good agreement with the theoretical ones, except for the higher molecular weight polymer. The observed difference may be attributed to the limits of the accuracy of estimation by ${ }^{1} \mathrm{H}$ NMR.

To find out whether the "click" reaction would proceed in the clay layers, we performed a model "click" reaction between azide-functionalized clay and commercially available propargyl methacrylate. After the "click" reaction, the characteristic azide signal near $2100 \mathrm{~cm}^{-1}$ has disappeared and a new signal near $1730 \mathrm{~cm}^{-1}$ corresponding to the carbonyl group of the methacrylate group has appeared (Figure 3 ). These FT-IR spectral observations are taken as an evidence for a successful "click" reaction.

Subsequently, alkyne-end group functionalized PTHF was attached into or onto the clay layers through "click" chemistry, which is to our knowledge the first example of a nanocomposite prepared via this nowadays quite popular chemical reaction. The

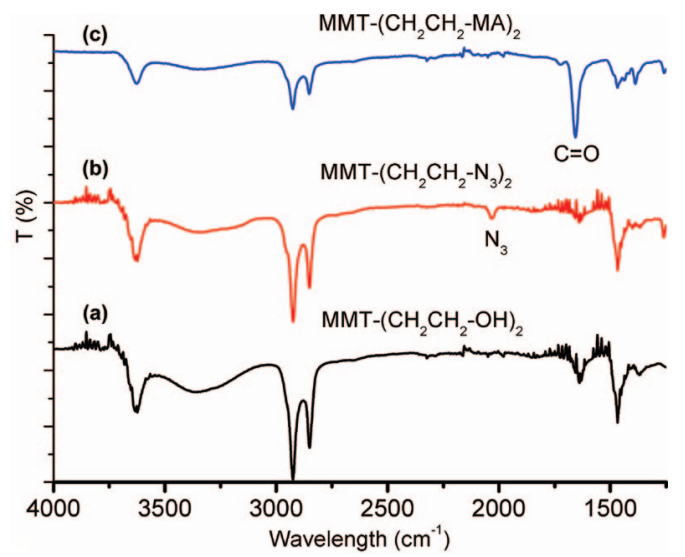

Figure 3. FT-IR spectra of hydroxyl-functionalized montmorillonite clay MMT- $\left(\mathrm{CH}_{2} \mathrm{CH}_{2}-\mathrm{OH}\right)_{2},($ a) $)$, azide-functionalized montmorillonite clay (MMT- $\left(\mathrm{CH}_{2} \mathrm{CH}_{2}-\mathrm{N}_{3}\right)_{2}$, (b)) and methacrylate functionalized montmorillonite clay (MMT- $\left(\mathrm{CH}_{2} \mathrm{CH}_{2}-\mathrm{MA}\right)_{2}$, (c)).
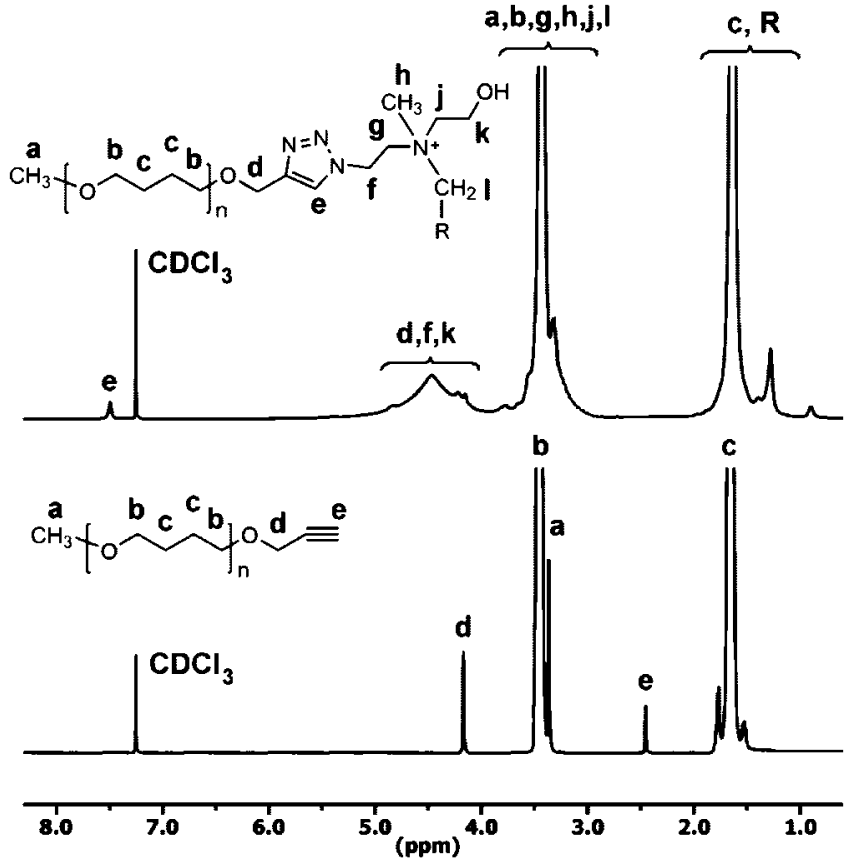

Figure 4. ${ }^{1} \mathrm{H}$ NMR spectra of alkyne terminated PTHF (a) and PTHF after "click" reaction and separation with $\mathrm{LiBr}(\mathrm{b})$.

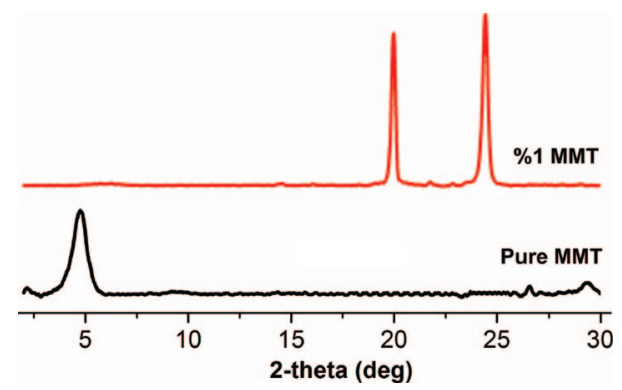

Figure 5. X-ray diffraction curves of pure MMT and PTHF-1\% MMT nanocomposite.

grafting of the polymer chains in between or onto clay layers triggers random exfoliation. The effectiveness of the "click" reactions was also evidenced by ${ }^{1} \mathrm{H}$ NMR analysis. Figure 4 shows the ${ }^{1} \mathrm{H}$ NMR spectra of the alkyne terminated PTHF and the separated polymer from the nanocomposite after "click" reaction. The spectrum of the initial polymer displays signals at 4.2 and $2.5 \mathrm{ppm}$, which correspond to the terminal alkyne group $\left(-\mathrm{CH}_{2}-\mathrm{C}^{\prime} \mathrm{CH}\right)$. The signal at $2.5 \mathrm{ppm}$ corresponding to the $\mathrm{CH}$ group of acetylene is significant in the characterization of the "click" reaction. After reaction, this peak is completely shifted to $7.5 \mathrm{ppm}$, corresponding to the aromatic proton of the triazole ring. The remaining signals in the spectra also agree with the proposed polymer structures. As mentioned earlier, other alkyne containing polymer structures, prepared by a variety of other available polymerization techniques such as ATRP, RAFT, and others, could be used in the same approach for the design of a wide range of novel nanocomposites.

Also, in the case of the nanocomposites obtained by "click" chemistry, the absence of a diffraction peak in the XRD analysis is consistent with an exfoliated structure. In Figure 5, an example is given for a nanocomposite containing $1 \mathrm{wt} \%$ of the MMT$\mathrm{N}_{3}$ azide-functionalized clay.

In Figure 6, TGA thermograms of PTHF/MMT nanocomposites, respectively, prepared by in situ polymerization (Figure $6 a$ ) and "click" reaction (Figure 6b), and of the compounds they are composed of are shown. All nanocomposites exhibit enhanced thermal stabilities compared to the virgin polymer. 

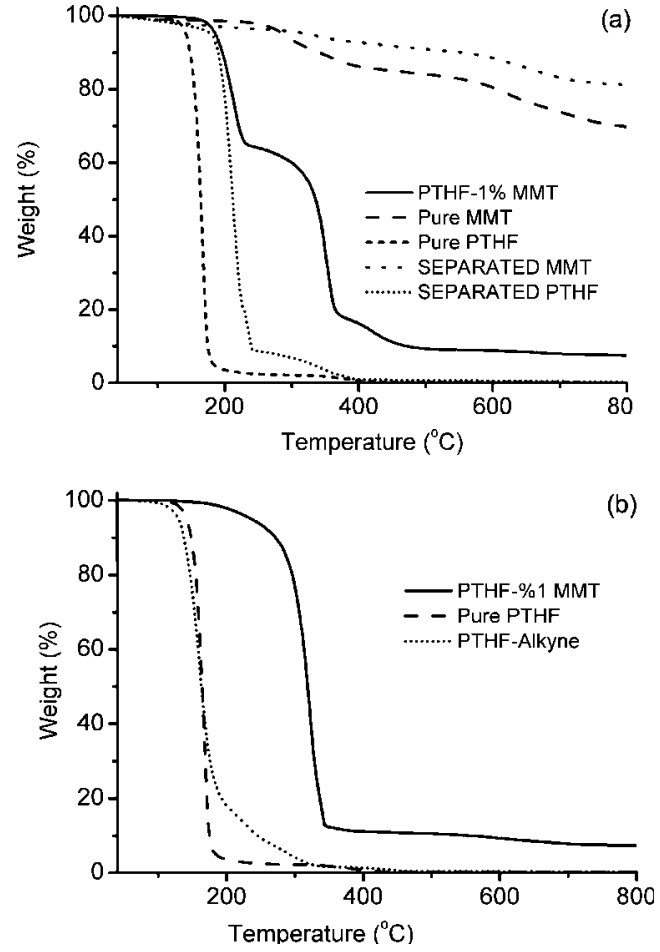

Figure 6. Weight loss for nanocomposites and corresponding compounds; pure PTHF, pure MMT, PTHF-1\%MMT nanocomposite by CROP, separated PTHF, and separated MMT (a), and pure PTHF, PTHF-alkyne, and PTHF-1\%MMT nanocomposite by "click" chemistry (b).

From the TGA data, it is clear that the decomposition onset and midpoint degradation temperature of all nanocomposites shifted significantly toward a higher temperature compared to those of the neat polymers. This result demonstrated that the resistance to thermal degradation is improved regardless of the preparation method. However, the nanocomposites prepared by in situ polymerization show to be thermally less stable than those prepared by the "click" chemistry approach. PTHF chains that for any reason fail to be anchored to the clay layers during the in situ polymerization are likely the cause of a lower thermal stability, resulting in a first degradation step at the decomposition temperature of unfilled PTHF. On the other hand, the thermograms of the nanocomposites obtained by "click" chemistry (Figure 6b) only show a single decomposition step that is increased about $115^{\circ} \mathrm{C}$ compared to nonfunctional PTHF obtained by the conventional method. This fact confirms the quantitative anchoring of the PTHF in the latter case and the advantage of this "click" approach compared to the in situ method.

The PTHF-clay nanocomposites obtained by both methods have also been analyzed by TEM (Figure 7). Regardless of the preparation method, any trace of remaining micron-sized clay aggregates could be detected throughout the studied samples. Rather thin clay nanoplatelets proved randomly distributed in the PTHF matrix, as shown by finely dispersed nanolayers as observed from their edge side, that is, thin contrasted filaments visible in Figure 7b (as highlighted by black arrows). However, as far as the composites prepared by in situ polymerization are concerned, although the absence of aggregates confirms the high degree of exfoliation of the layered silicates, some small intercalated stacks with a thickness of a few tenths of nanometers remain from time to time as observed in Figure 7a. This may be due to the incomplete activation of hydroxyl group and although at limited rate, some transfer reactions occurred during the in situ polymerization. Thus, the "click" method appears to be more versatile as the functional chains are prepared inde-
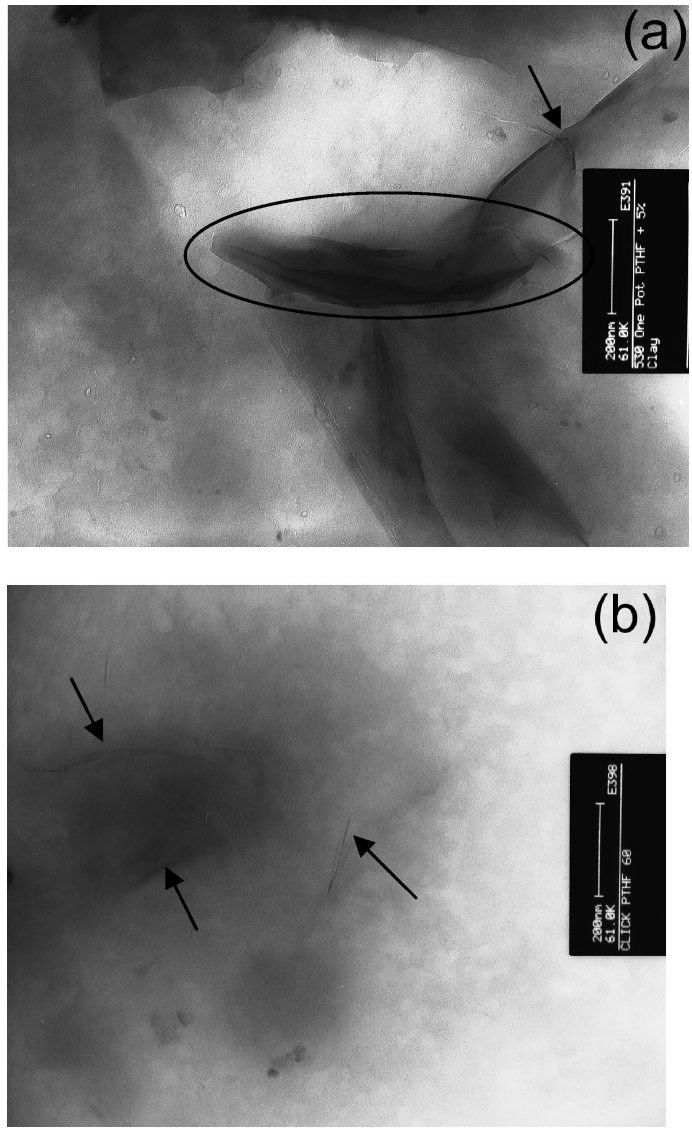

Figure 7. TEM images of PTHF-5\%MMT nanocomposite by CROP (a) and PTHF-1\%MMT nanocomposite by "click" chemistry (b).

pendently without any undesired side reactions and tethered to the layers through the efficient "click" reaction.

\section{Conclusions}

In conclusion, PTHF/clay nanocomposites have been prepared in two different ways, respectively by in situ CROP and "click" chemistry processes. The in situ grafting from polymerization, taking place between the clay layers, not only leads to PTHF chains with well-defined structures but also to a highly exfoliated morphology. On the other hand, the "click" grafting to method is simple and distinctly differentiates from existing techniques since it is quantitative and no byproduct is formed, leading to thermally more stable nanocomposites. Moreover, this approach opens new pathways for polymer-clay composites designing intercalating agents capable of undergoing "click" reaction. It is now possible to prepare such agents by the polymerization of appropriate monomers by means of recently developed controlled polymerization methods. Further studies in this line are now in progress.

Acknowledgment. One of the authors (M.A.T.) thanks Tubitak (Turkish Scientific and Technological Council) for the financial support by means of a doctoral fellowship. F.D.P. and P.D. acknowledge the Belgian Programme on Interuniversity Attraction Poles initiated by the Belgian State, Prime Minister Office (P6/ 27), for financial support.

\section{References and Notes}

(1) Giannelis, E. P. Adv. Mater. 1996, 8 (1), 29-35.

(2) Okamoto, M. Mater. Sci. Technol. 2006, 22 (7), 756-779.

(3) Ray, S. S.; Okamoto, M. Prog. Polym. Sci. 2003, 28 (11), 1539-1641.

(4) Alexandre, M.; Dubois, P. Mater. Sci. Eng., R 2000, 28 (1-2), 1-63. 
(5) Ma, J.; Xu, H.; Ren, J. H.; Yu, Z. Z.; Mai, Y. W. Polymer 2003, 44 (16), 4619-4624.

(6) Kubies, D.; Pantoustier, N.; Dubois, P.; Rulmont, A.; Jerome, R. Macromolecules 2002, 35 (9), 3318-3320.

(7) Lepoittevin, B.; Pantoustier, N.; Devalckenaere, M.; Alexandre, M.; Kubies, D.; Calberg, C.; Jerome, R.; Dubois, P. Macromolecules 2002 35 (22), 8385-8390.

(8) Viville, P.; Lazzaroni, R.; Pollet, E.; Alexandre, M.; Dubois, P. J. Am. Chem. Soc. 2004, 126 (29), 9007-9012.

(9) Di, J. B.; Sogah, D. Y. Macromolecules 2006, 39 (15), 5052-5057.

(10) Di, J. B.; Sogah, D. Y. Macromolecules 2006, 39 (3), 1020-1028.

(11) Weimer, M. W.; Chen, H.; Giannelis, E. P.; Sogah, D. Y. J. Am. Chem. Soc. 1999, 121 (7), 1615-1616.

(12) Zhao, H. Y.; Farrell, B. P.; Shipp, D. A. Polymer 2004, 45 (13), 44734481.

(13) Zhao, H. Y.; Shipp, D. A. Chem. Mater. 2003, 15 (14), 2693-2695.

(14) Konn, C.; Morel, F.; Beyou, E.; Chaumont, P.; Bourgeat-Lami, E. Macromolecules 2007, 40 (21), 7464-7472.

(15) Zhang, B. Q.; Pan, C. Y.; Hong, C. Y.; Luan, B.; Shi, P. J. Macromol. Rapid Commun. 2006, 27 (2), 97-102.

(16) Salem, N.; Shipp, D. A. Polymer 2005, 46 (19), 8573-8581.

(17) Wheeler, P. A.; Wang, J. Z.; Mathias, L. J. Chem. Mater. 2006, 18 (17), 3937-3945.

(18) Li, C. P.; Huang, C. M.; Hsieh, M. T.; Wei, K. H. J. Polym. Sci., Part A: Polym. Chem. 2005, 43 (3), 534-542.

(19) Zhao, H. Y.; Argoti, S. D.; Farrell, B. P.; Shipp, D. A. J. Polym. Sci., Part A: Polym. Chem. 2004, 42 (4), 916-924.

(20) Bottcher, H.; Hallensleben, M. L.; Nuss, S.; Wurm, H.; Bauer, J.; Behrens, P. J. Mater. Chem. 2002, 12 (5), 1351-1354.

(21) Tseng, C. R.; Wu, J. Y.; Lee, H. Y.; Chang, F. C. J. Appl. Polym. Sci. 2002, 85 (7), 1370-1377.

(22) Fu, X.; Qutubuddin, S. Polymer 2001, 42 (2), 807-813.

(23) Fu, X.; Qutubuddin, S. Mater. Lett. 2000, 42 (1-2), 12-15.

(24) Uthirakumar, P.; Song, M. K.; Nah, C.; Lee, Y. S. Eur. Polym. J. 2005, 41 (2), 211-217.

(25) Uthirakumar, P.; Nahm, K. S.; Hahn, Y. B.; Lee, Y. S. Eur. Polym. J. 2004, 40 (11), 2437-2444.

(26) Nese, A.; Sen, S.; Tasdelen, M. A.; Nugay, N.; Yagci, Y. Macromol. Chem. Phys. 2006, 207 (9), 820-826.
(27) Yu, Y. H.; Lin, C. Y.; Yeh, J. M. J. Appl. Polym. Sci. 2004, 91 (3), 1904-1912.

(28) Fan, X. W.; Zhou, Q. Y.; Xia, C. J.; Cristofoli, W.; Mays, J.; Advincula, R. Langmuir 2002, 18 (11), 4511-4518.

(29) Dreyfuss, P. In Handbook of Elastomers; Bhowmick, A. K., Stephens, H., Eds.; Marcel Dekker, Inc, New York, NY, 2001; pp 723-733.

(30) Rostovtsev, V. V.; Green, L. G.; Fokin, V. V.; Sharpless, K. B. Angew. Chem., Int. Ed. 2002, 41 (14), 2596-2599.

(31) Kolb, H. C.; Finn, M. G.; Sharpless, K. B. Angew. Chem., Int. Ed. 2001, 40 (11), 2004-2021.

(32) Hawker, C. J.; Wooley, K. L. Science 2005, 309 (5738), 1200-1205.

(33) Lutz, J. F. Angew. Chem., Int. Ed. 2007, 46 (7), 1018-1025.

(34) Fournier, D.; Hoogenboom, R.; Schubert, U. S. Chem. Soc. Rev. 2007, $36(8), 1369-1380$.

(35) Altintas, O.; Yankul, B.; Hizal, G.; Tunca, U. J. Polym. Sci., Part A: Polym. Chem. 2006, 44 (21), 6458-6465.

(36) Gacal, B.; Durmaz, H.; Tasdelen, M. A.; Hizal, G.; Tunca, U.; Yagci, Y.; Demirel, A. L. Macromolecules 2006, 39 (16), 5330-5336.

(37) Opsteen, J. A.; van Hest, J. C. M. Chem. Commun. 2005, (1), 57-59.

(38) Evans, R. A. Aust. J. Chem. 2007, 60 (6), 384-395.

(39) Fleming, D. A.; Thode, C. J.; Williams, M. E. Chem. Mater. 2006, 18 (9), 2327-2334.

(40) Binder, W. H.; Sachsenhofer, R.; Straif, C. J.; Zirbs, R. J. Mater. Chem. 2007, 17 (20), 2125-2132.

(41) Ranjan, R.; Brittain, W. J. Macromolecules 2007, 40 (17), 6217-6223.

(42) Voggu, R.; Suguna, P.; Chandrasekaran, S.; Rao, C. N. R. Chem. Phys. Lett. 2007, $443(1-3), 118-121$.

(43) Bakbak, S.; Leech, P. J.; Carson, B. E.; Saxena, S.; King, W. P.; Bunz, U. H. F. Macromolecules 2006, 39 (20), 6793-6795.

(44) Johnson, J. A.; Lewis, D. R.; Az, D. D. D. U.; Finn, M. G.; Koberstein, J. T.; Turro, N. J. J. Am. Chem. Soc. 2006, 128 (20), 6564-6565.

(45) Dubreuil, M. F.; Goethals, E. J. Macromol. Chem. Phys. 1997, 198 (10), 3077-3087.

(46) Parrish, B.; Breitenkamp, R. B.; Emrick, T. J. Am. Chem. Soc. 2005, 127 (20), 7404-7410.

(47) Tong, J. D.; Du Prez, F. E.; Goethals, E. J. Macromolecules 2001, 34 (4), 761-767.

MA801149X 